\title{
OBSERVATIONS ON THE DEVELOPMENT OF DELTA PHASE IN IN718 ALLOY
}

\author{
F.P. Cone \\ Pratt \& Whitney, United Technologies \\ West Palm Beach, Florida
}

\begin{abstract}
A wide variety of microstructures may be developed in wrought IN718. While billet chemistry and thermomechanical process history directly relate to the resulting general microstructure it may be difficult at times to understand how particular structures were formed. The appearance, morphology and control of $\delta$ phase are of special interest because of its critical influcnce on grain structure, grain size and mechanical properties. This paper reviews the evolution of microstructure during the deformation and heat treatment of plate rolled samples with the goal of increasing the understanding of how different morphologies of $\delta$ may form and how they will respond to further processes. Processing began with a forging heat treated above the $\delta$ solvus and then either exposed to a $\delta$ precipitation cycle followed by sub $\delta$ solvus rolling or rolled below the $\delta$ solvus followed by $\delta$ precipitation. Qualitative evaluations of the resulting microstructures provide insight into the mechanisms controlling the development and morphology of $\delta$ phase. Consideration will also be given to processes for evaluating uniformity in IN718 forgings. The information presented may assist those involved in the manufacture and use of IN718 articles where microstructure control is sought.
\end{abstract}

Superalloys 718, 625, 706 and Various Derivatives

Edited by E.A. Loria

T.MS (The Minerals, Metals \& Materials Society), 2001 


\section{Introduction}

$\delta$ phase plays a significant role in the development of microstructure and properties of IN7 18 . Numerous papers describe using $\delta$ phase to control microstructure and related mechanical behavior [1-3]. At times the microstructures of forgings and rolled rings display unusual concentrations of $\delta$ phase or non-uniform grain sizes that may be problematic for full life service. Attempts to unravel how the process history contributes to the resultant condition can be difficult to determine when the microstructures developed in prior processing are unavailable. The operations applied in this experiment were not intended to represent a particular part process but instead to form $\delta$ and then process it. $\delta$ phase was developed along two different process paths and then observations were made during subsequent deformation and annealing treatments. In one series $\delta$ was developed first and then subjected to deformation. In the other sequence deformation preceded the intentional $\delta$ precipitation and further deformation followed. By following the evolution of $\delta$ through precipitation and deformation it was hoped that more knowledge about the phase and how it can be used to control microstructure would result.

\section{Experimental procedure}

\section{Material}

The starting stock for these deformation studies consisted of sections of a fully heat treated AMS 5663 ring forging. The composition of the 8 -in. diameter billet used to produce the part is shown in Table I.

Table I Nominal composition (weight percent) of material used in this study.

\begin{tabular}{|c|c|c|c|c|c|c|c|c|c|}
\hline $\mathrm{Ni}$ & $\mathrm{Fe}$ & $\mathrm{Cr}$ & $\mathrm{Ti}$ & $\mathrm{Al}$ & $\mathrm{Mo}$ & $\mathrm{Nb}+\mathrm{Ta}$ & $\mathrm{C}$ & $\mathrm{Mn}$ & $\mathrm{Si}$ \\
\hline 54.12 & 17.43 & 17.91 & 1.01 & 0.45 & 2.88 & 5.45 & 0.025 & 0.07 & 0.07 \\
\hline
\end{tabular}

\section{Processing}

Samples were machined from the same region of the ring to provide rectangular slabs that were rolled in the same orientation and direction the metal had experienced during ring rolling. The specimens were approximately $25 \mathrm{~mm}$ thick at the start of rolling. All material was annealed at $1054 \mathrm{C}$ for 60 minutes and static air cooled prior to any further processing. A sufficient number of samples were created to allow each slab its own particular level of rolling strain. A variety of process paths were applied including anneals above and below the $\delta$ solvus to purposefully solution or generate $\delta$ phase. Prior to rolling samples were heated for 1 hour at the rolling temperature. Rolling was conducted in increments of $10 \%$ reduction in thickness for each heating cycle on Pratt \& Whitney Florida's Material's Laboratory cold rolling mill. The rolls have a diameter of approximately $25.4 \mathrm{~cm}$, the roll speed was about $15 \mathrm{~cm} / \mathrm{second}$ and the estimated strain rate was $0.4 / \mathrm{sec}$. Samples that had completed their prescribed amount of deformation were allowed to air cool. Samples that required additional reduction to achieve their particular amount of total strain were immediately returned to the furnace for a 15 minute heating cycle and then rolled again. Table II outlines the various processing conditions used. Both the DR and RD series of specimens were processed sequentially (i.e., DR1 lead to DR2 lead to DR3 and so on). Microstructure evaluations were conducted at each step along the process path to allow the evolution of changes to be observed. The longitudinal sections examined were from mid length and mid width of the rolled coupons. 
Process Selection

The conditions applied to the material of this study were chosen for a varicty of reasons. Heating the material at $1054 \mathrm{C}$ was intended to normalize the microstructure to a uniform grain condition free from the $\delta$ precipitates to be developed in subsequent processing. $899 \mathrm{C}$ heating was applied to give this relatively $\mathrm{Nb}$ rich material opportunity to develop $\delta$ phase near the precipitation maxima [4]. $982 \mathrm{C}$ heating and rolling exposures were used as sub $\delta$ solvus solution cycles that allow relatively fine grains to be formed while partial solutioning $\delta$ and full solutioning any $\gamma^{\prime}$ phase that may be present. Process sequences were chosen to allow rolling of $\delta$ rich structures, and to assess how prior processing affects modes of $\delta$ precipitation. Reductions at increments of only $10 \%$ were intended to simulate ring rolling and provide marginal forging conditions that may be present in many forming scenarios. Recrystallization during this study is believed to be primarily static, occurring either immediately following rolling or during re-heating. Previous studies indicated a true strain of 0.1 , at $982 \mathrm{C}$ and moderate rates of strain would be insufficient to allow peak flow stresses to be reached and softening due to dynamic recrystallization was not likely to have occurred during rolling $[5,6]$.

Table II Outline of process path used during the microstructure development study.

\begin{tabular}{|c|c|}
\hline \multicolumn{2}{|c|}{$\begin{array}{l}\text { Baseline } \\
1054 \text { C Anneal, } 1 \text { hour, Air cool } \\
(1930 \mathrm{~F})\end{array}$} \\
\hline $\begin{array}{c}\text { DR } 1 \\
899 \mathrm{C}, 8 \text { hours, air cool } \\
(1650 \mathrm{~F})\end{array}$ & $\begin{array}{l}\text { RD1 } \\
982 \text { C Rolling } \\
(1800 \mathrm{~F})\end{array}$ \\
\hline $\begin{array}{l}\text { DR2 } \\
982 \mathrm{C} \mathrm{Rolling} \\
(1800 \mathrm{~F})\end{array}$ & $\begin{array}{c}\text { RD2 } \\
899 \mathrm{C}, 8 \text { hours, air cool } \\
(1650 \mathrm{~F})\end{array}$ \\
\hline $\begin{array}{l}\text { DR3 } \\
982 \mathrm{C}, 1 \text { hour, air cool } \\
(1800 \mathrm{~F})\end{array}$ & $\begin{array}{l}\text { RD3 } \\
982 \text { C Rolling } \\
(1800 \mathrm{~F})\end{array}$ \\
\hline $\begin{array}{c}\text { DR4 } \\
899 \mathrm{C}, 8 \text { hours, air cool } \\
(1650 \mathrm{~F})\end{array}$ & $\begin{array}{c}\text { RD4 } \\
982 \mathrm{C}, 1 \text { hour, air cool } \\
(1800 \mathrm{~F})\end{array}$ \\
\hline
\end{tabular}

\section{Results and Discussion}

\section{Hot solution with $\delta$ precipitation followed by rolling}

Baseline - Solutioning at $1054 \mathrm{C}$ generated a uniform grain size approximately ASTM 3 with scattered carbides (Figure 1). 

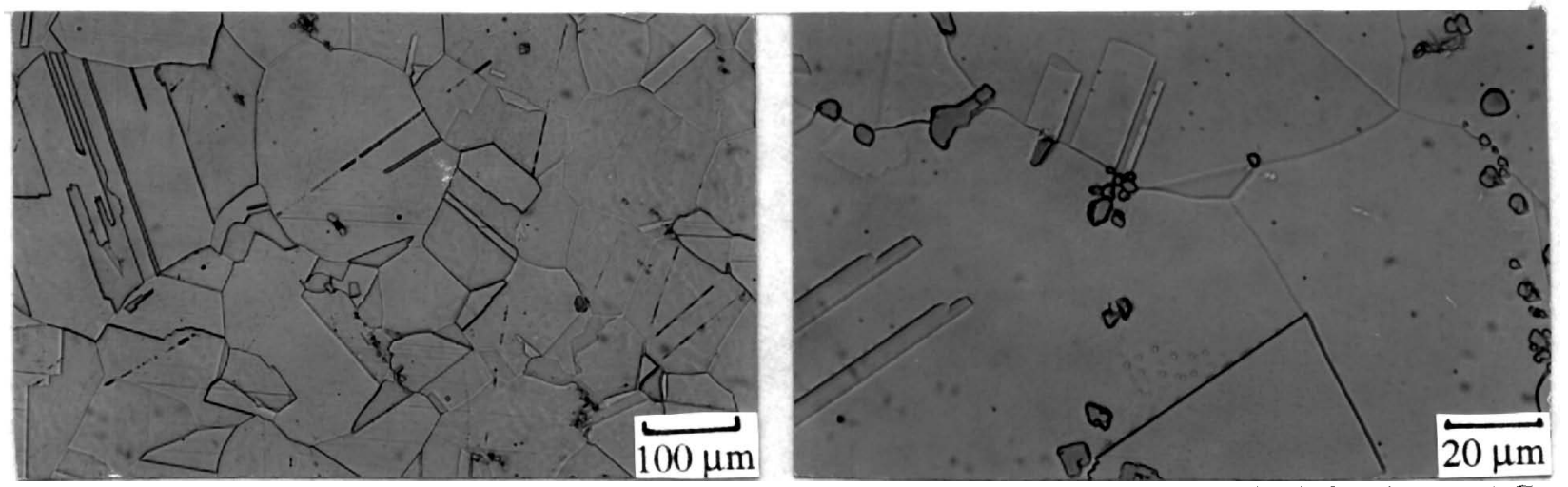

Figure 1: The Baseline microstructure for material applied in this study. $1054 \mathrm{C}, 1$ hour, AC.

Condition DR1 - The $899 \mathrm{C}$ exposure developed grain and twin boundary $\delta$ precipitates with what appears to be a background of $\gamma^{\prime}$ consistent with previous work [6] (Figure 2). Heterogeneous precipitation of $\delta$ may be expected in a relatively strain free system [7]. The lack of appreciable $\delta$ within the grains is likely due to the reduced number of dislocation sites of sufficient energy to facilitate development. The development of a more uniform distribution of Widmanstatten $\delta$ throughout a grain structure can be related to quenching strains or the remnant strains within unrecrystallized grains $[3,4,8]$.
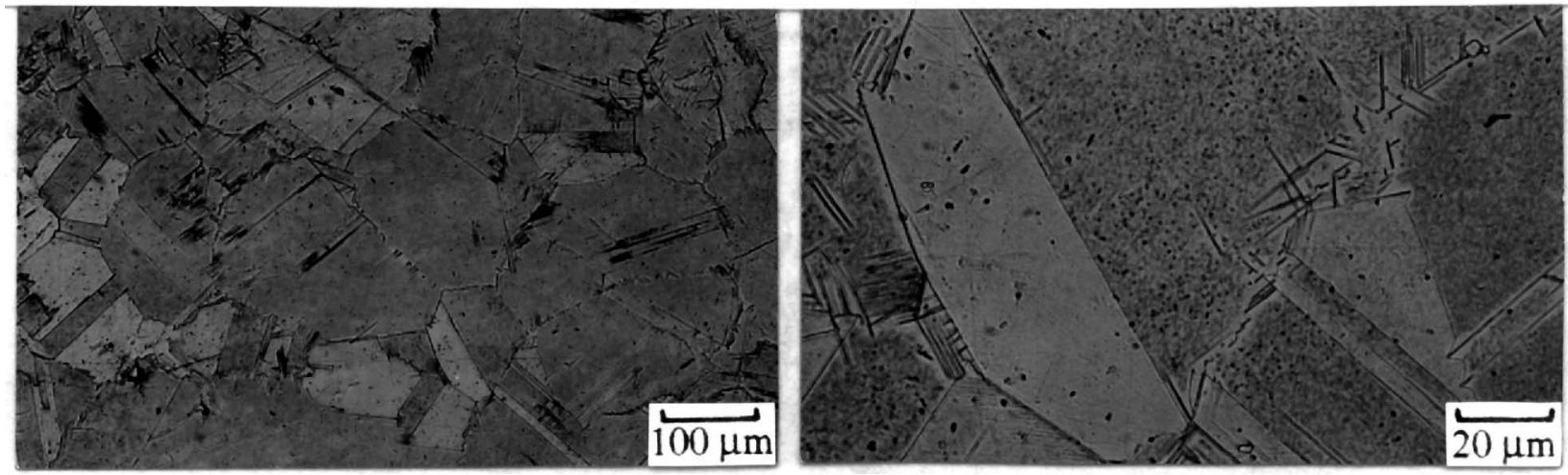

Figure 2: Microstructure of material condition DR1. $899 \mathrm{C}$ for 8 hours, AC.

Condition DR2 - Heating for rolling at $982 \mathrm{C}$ does little to the $\delta$ laths while dissolving the $\gamma^{\prime}$ completely (Figure 3). Rolling at $982 \mathrm{C}$ progressively distorts the grain structure with the $\delta$ laths becoming more disturbed and interrupted at $30 \%$ reduction and degenerating largely into chains at $50 \%$ reduction. The combination of hot mechanical strain and intermittent annealing breaks up the long range lath $\delta$ and set the stage for creating spheroidal or tablet shaped $\delta$ (Figure 4).
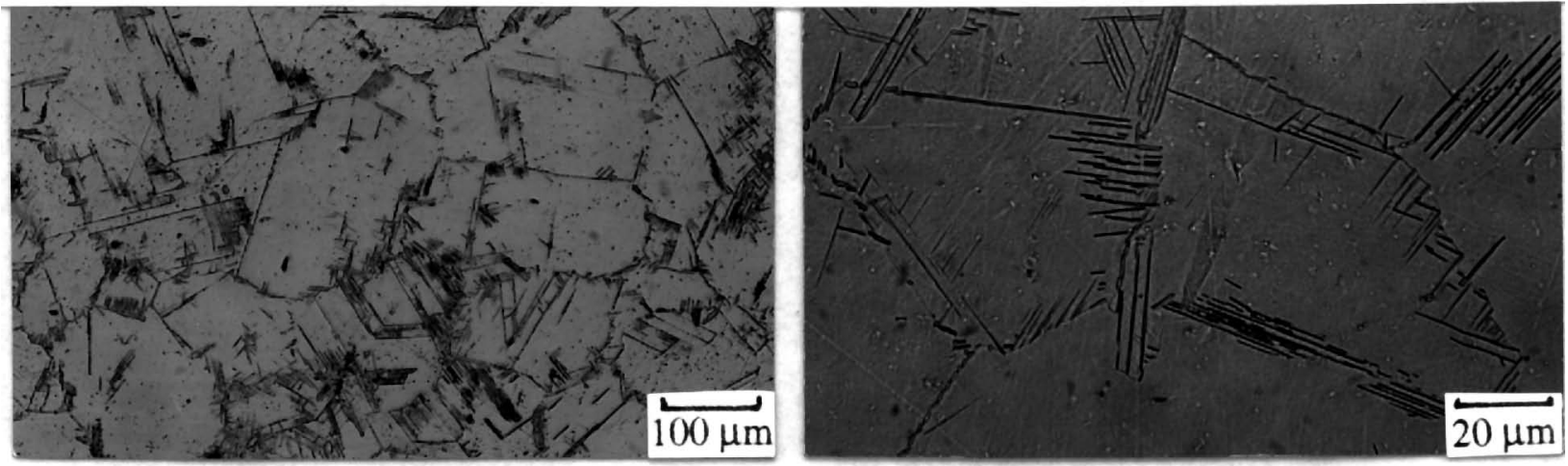

Figure 3: Microstructure of material condition DR2 prior to deformation. 

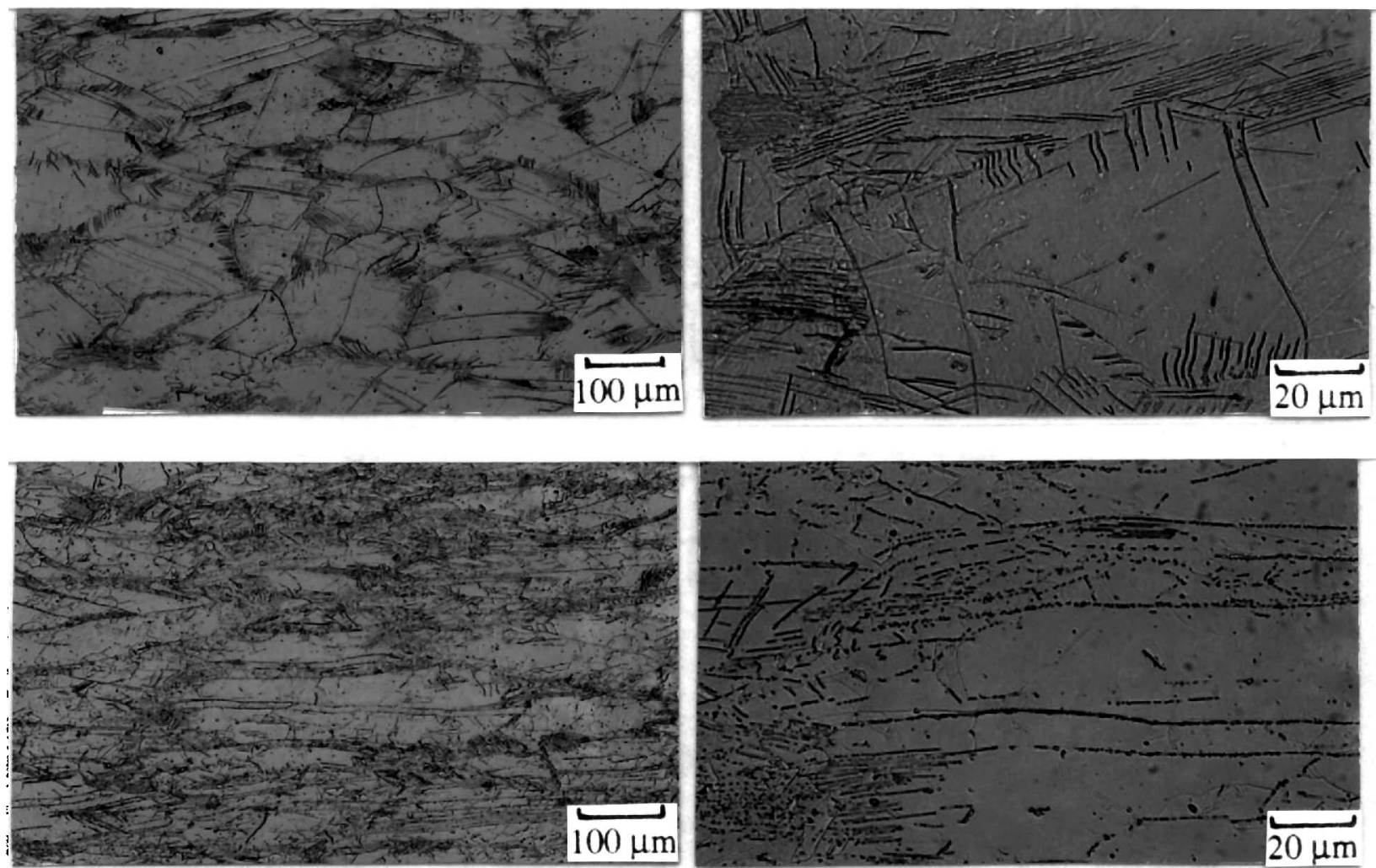

Figure 4: Microstructure of material condition DR2 at $30 \%$

(Top) and $50 \%$ (Bottom) total reduction at $982 \mathrm{C}$.

Condition DR3 - Subsequent annealing at $982 \mathrm{C}$ for one hour appears to recrystallize much of the material that has been through at least $30 \%$ reduction to a very fine grain size ASTM 12. However, the original grain structure highlighted by broken $\delta$ is still very evident (Figure 5) and it is difficult to see the new grains.
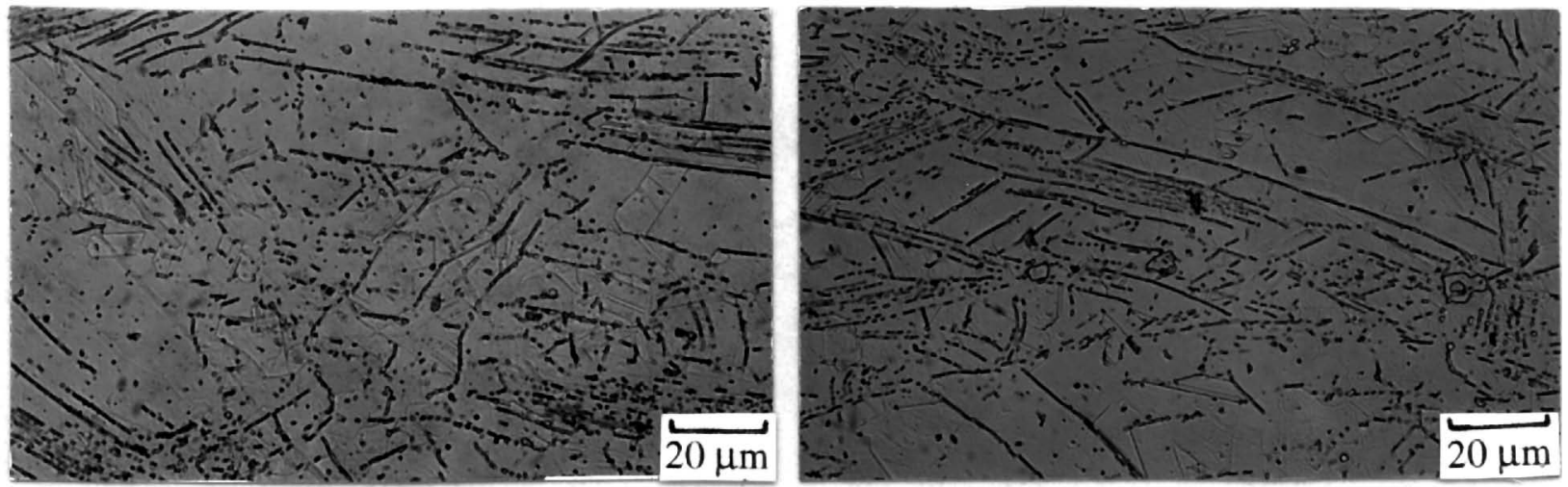

Figure 5: Microstructure of material condition DR3 after 30\% (left) and $50 \%$ (right) total reduction, $982 \mathrm{C}$ followed by $982 \mathrm{C}, 1$ hour, $\mathrm{AC}$.

Condition DR4 - The final anneal at $899 \mathrm{C}$ shows that lath $\delta$ can be readily developed again and the microstructure becomes very congested with various forms of $\delta$ phase (Figure 6). Close inspection of the specimens at 20 to $50 \%$ prior reductions reveals the nature of the different $\delta$ morphologies. Spheroidal $\delta$ appears in those locations favored by higher rolling strains and the concentrations of $\delta$ produced in the original $899 \mathrm{C}$ precipitation, the grain boundaries of the original $1054 \mathrm{C}$ solution anneal. The volume fraction of spheroidal $\delta$ is $l o w$ 
for the lower reductions but also low in general because not much $\delta$ was formed in the initial $899 \mathrm{C}$ treatment prior to rolling. A few particular grain and twin boundaries show nearly continuous $\delta$ phase that has stubbornly resisted deformation and solutioning and outline the original grains formed at $1054 \mathrm{C}$. Distorted $\delta$ phase is present in roughly parallel layers that appear to be on the verge of becoming spheroidal. There are patches of fresh lath $\delta$ that are forming within the spaces not occupied by the spheroidal or distorted $\delta$. The appearance of this new or fresh $\delta$ lath may indicate areas of strain within the microstructure that have not been fully recrystallized. At the $50 \%$ reduction level the scale or span of the $\delta$ lath is much more limited than at $20 \%$. Also, a background decoration of $\gamma$ ' particles appears among the more widely separated $\delta$ laths where $\mathrm{Nb}$ had remained in solution.
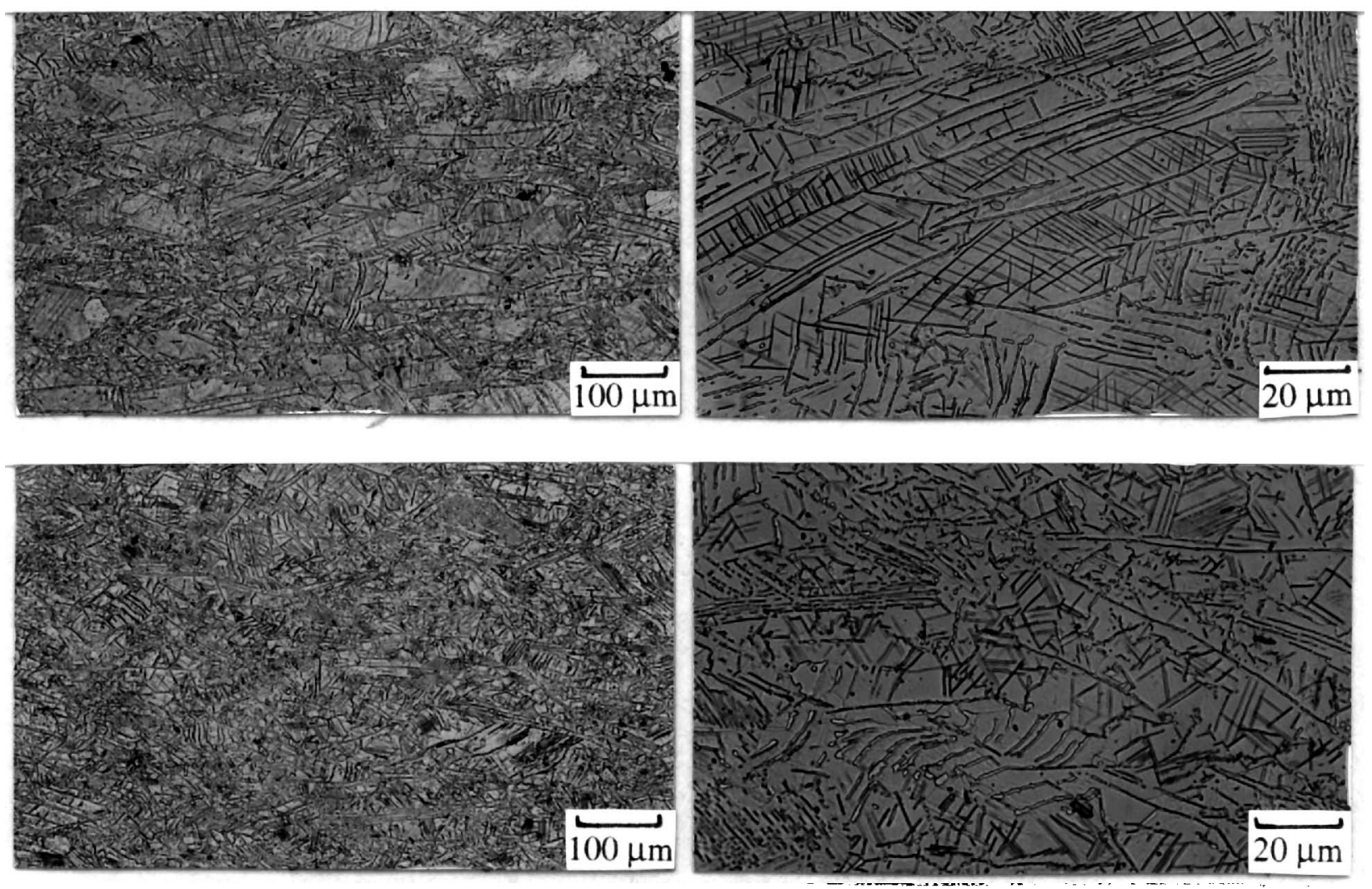

Figure 6: Microstructure of material condition DR4 after $899 \mathrm{C}, 8$ hours, AC for material rolled 20\% (Top) and 50\% (Bottom) and heat treated at $982 \mathrm{C}$.

\section{Hot solution with rolling followed by $\delta$ precipitation}

Condition RD1 - Starting with the same base microstructure as described above, rolling at 982 $\mathrm{C}$ again progressively distorts the grain structure. However, for this process path, as time and the amount of work are increased at $982 \mathrm{C}$. more and more $\delta$ phase appears (Figure 7). At 20\% reduction (two heating cycles at $982 \mathrm{C}$ ) $\delta$ is marginally present. At $50 \%$ total reduction (five heating cycles and associated higher strain) small chopped up particles of $\delta$ phase appear within the grains and along grain boundaries. Lower magnification viewing reveals a layered morphology of fine $\delta$ traversing grain boundaries indicating an overall segregation of $\mathrm{Nb}$ inherent in the original barstock. This "banded" distribution of solute complicates microstructure interpretation in that metal with two levels of $\mathrm{Nb}$ effectively has two $\delta$ solvii and associated thermo-mechanical process responses. Studies within Pratt \& Whitney have documented variations of 1.4 wt. \% Nb sufficiont to develop banded structures [9]. 
Segregation in highly alloyed materials is not unexpected but considering the uniformity of the grain structure at the start of this study it was surprising to see after rolling at $982 \mathrm{C}$. However, considering that deformation was at a relatively constant temperature just below the $\delta$ solvus, only those areas rich enough in $\mathrm{Nb}$ were able to develop $\delta$. Forging within a falling temperature range or at a lower temperature would not likely show this condition due to the greater volume of $\delta$ that could be developed.
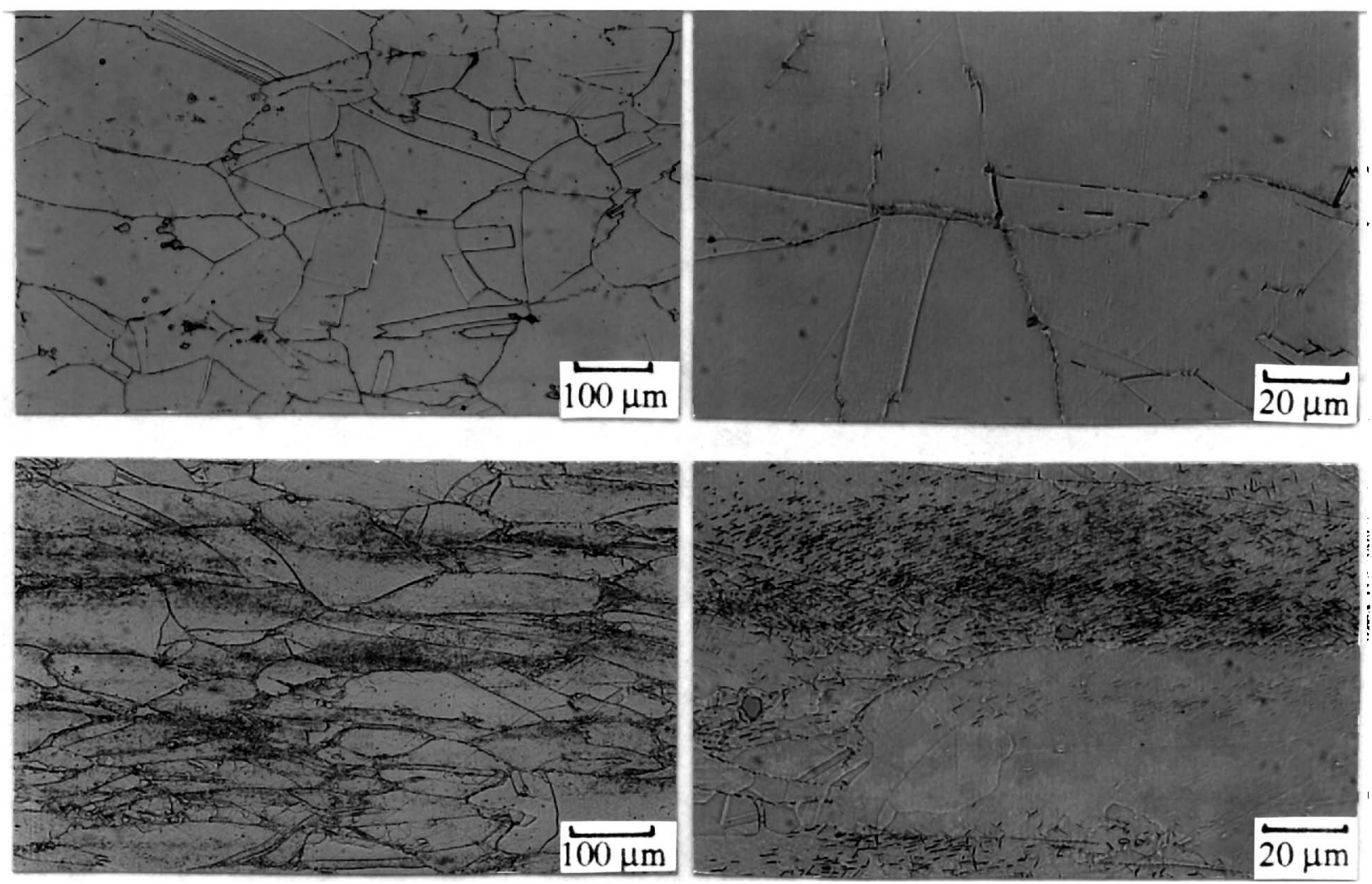

Figure 7: Microstructure for material condition RD1 at 20\%

(Top) and 50\% (Bottom) total reduction, $982 \mathrm{C}$.

Condition RD2 - Processing and evaluation was now focused on material which had an initial $20 \%$ reduction at $982 \mathrm{C}$ followed by exposure to $899 \mathrm{C}$ for 8 hours (Figure 8 ). In this condition $\delta$ has precipitated as medium range laths across grain boundaries and within the grains accompanied by $\gamma$ '. Comparison with Figure 2 shows that $20 \%$ reduction at $982 \mathrm{C}$ was sufficient strain to set up the substructure necessary for $\delta$ to come out within the grains.
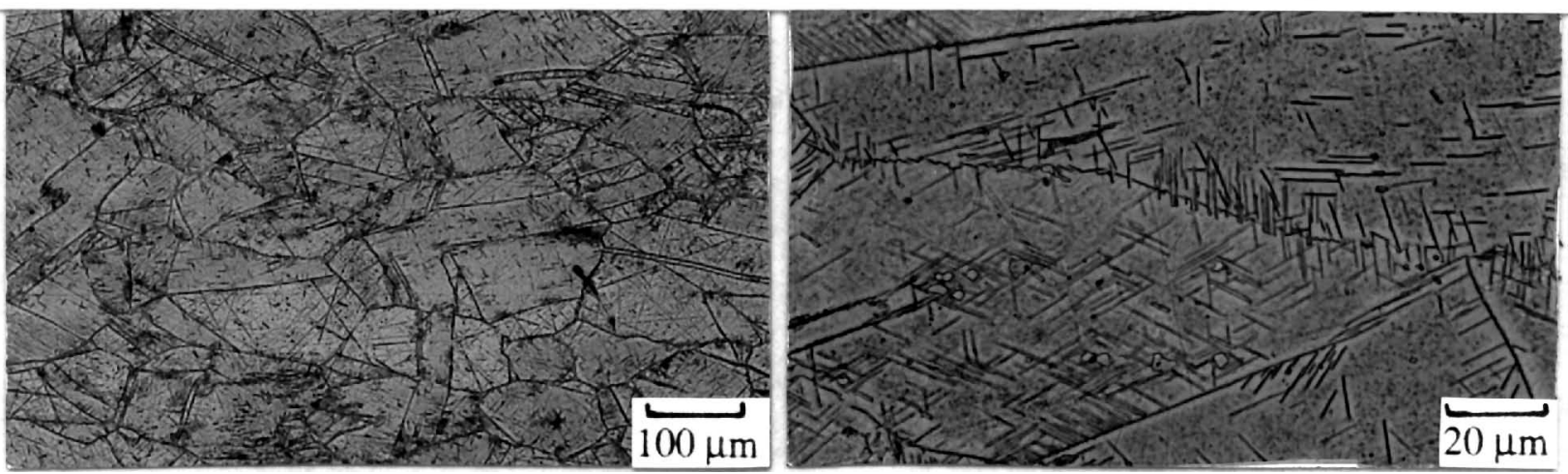

Figure 8: Microstructure for material condition RD2 after 899

$\mathrm{C}, 8$ hours, AC on material rolled $20 \%$ total reduction, $982 \mathrm{C}$. 
Condition RD3 - Rolling reductions were resumed at $982 \mathrm{C}$ for material that had been rolled at $20 \%$ at $982 \mathrm{C}$ and given the $899 \mathrm{C} \delta$ cycle. Rolling at $982 \mathrm{C}$ begins to break up the grain boundary $\delta$ at $20 \%$ but does little to disturb $\delta$ within the grains. At $50 \%$ reduction only a few laths have not been broken up and a large amount of spheroidal $\delta$ is present. Coarser grains are noted in the areas lean in $\delta$ (Figure 9).

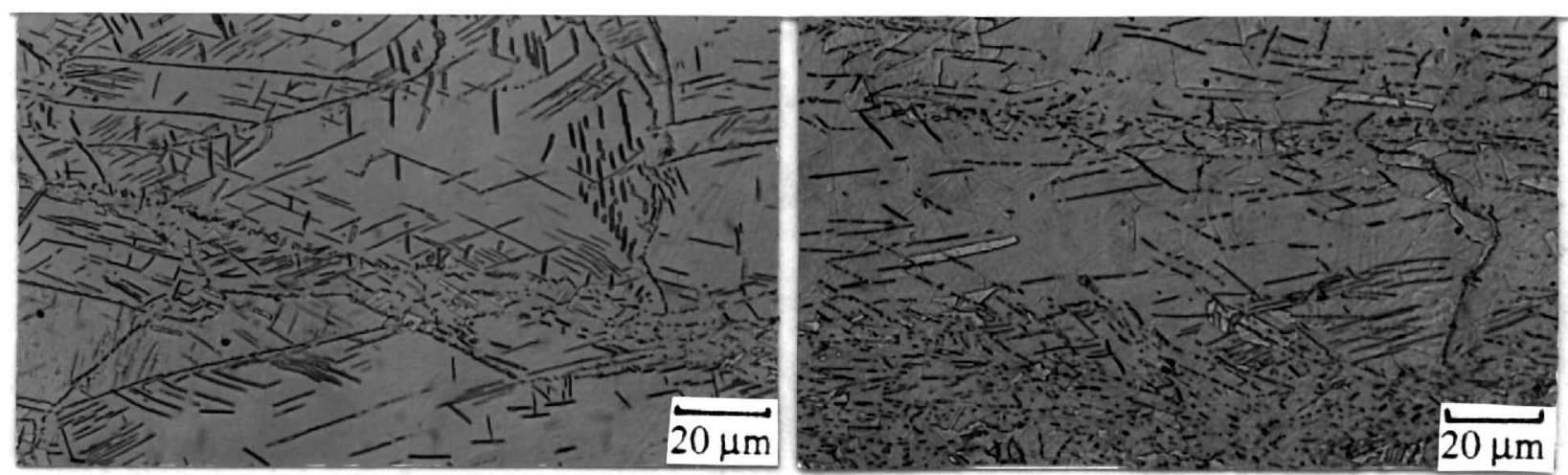

Figure 9: Microstructure for material condition RD3 at an additional 20\%

(Left) and $50 \%$ total reduction (Right), $982 \mathrm{C}$ on material condition RD2.

Condition RD4 - Annealing at 982C after rolling at 982C did little to change the as-rolled microstructure until the $50 \%$ prior reduction level where virtually all lath $\delta$ has been disrupted into spheroidal particles (Figure 10). The coincident grain size and $\delta$ structure giadients within the sample are presumed to be additional evidence of a $\mathrm{Nb}$ composition variation within the metal. Many other studies have also noted similar duplex grain size distributions of coarse unrecrystallized or partially recovered grains surrounded by a necklace of fine recrystallized grains [2,3,5-7].

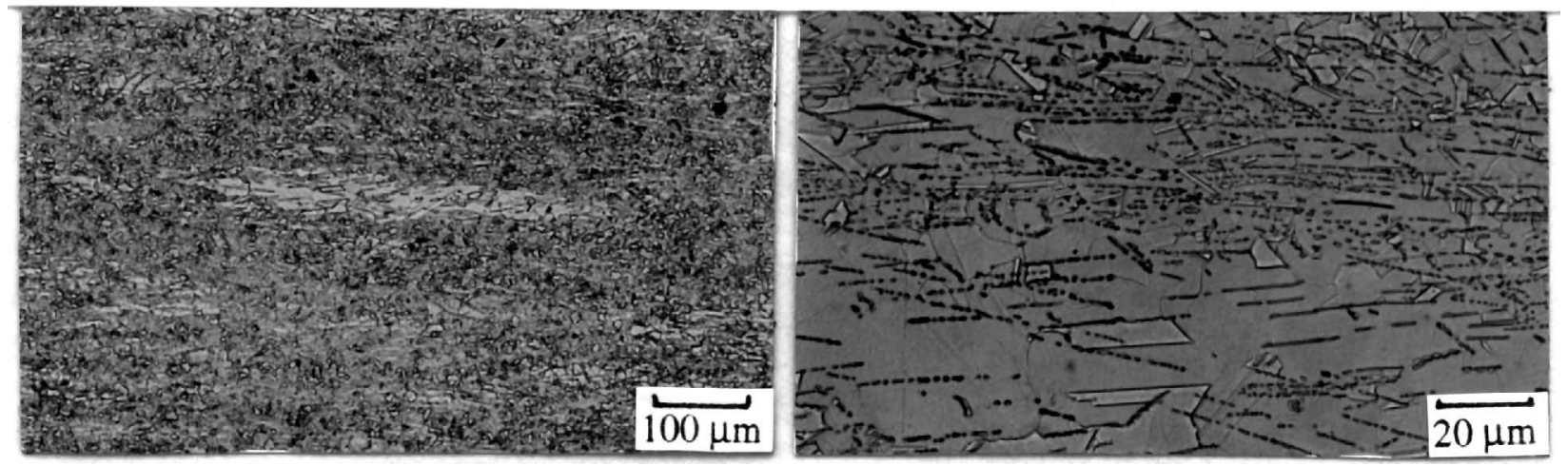

Figure 10: Microstructure for material condition RD4 after 982

$\mathrm{C}, 1$ hour, AC on material RD3 rolled $50 \%$ total reduction.

In light of the composition and microstructure gradients observed in the RD series, the DR series specimens were revisited and some evidence of banding was found in the DR2 and DR3 material at the $50 \%$ reduction level (Figures 4 and 5 ). Below $40 \%$ total reduction the grain boundary concentration of $\delta$ appears evenly distributed. At $50 \%$ reduction the variations in $\delta$ phase and grain size begin to appear. It may be theorized that when a fine grain envelope is established around a coarse grain, that grain will be insulated from much of the nominal deformation if the reductions are slight or incremental in nature. The fine grains may accommodate the majority of plastic strain and only enough strain to provide for annealing recovery with elongation but no refinement of the coarser grains. The subtle banding of these samples may also be due to composition gradients where differences in local $\delta$ solvus temperature set up non-uniform $\delta$ barriers to grain size changes during forging and annealing. 
This author suggests a combination of both mechanisms may be acting. The composition gradient sets the stage for coarse grains and once they become trapped in the field of fine grains they appear to resist refinement because the fine grains preferentially use up the strain. Perhaps the microstructures of DR4 show a way to achieve uniform grain structure in the presence of composition gradients. Figure 6 shows that with a second $\delta$ precipitation treatment, material with a $50 \%$ prior reduction of an initial grain boundary $\delta$ structure now develops a much more uniform distribution of $\delta$, albeit of various morphologies.

A review of the observations made on the development of $\delta$ phase in IN 718 finds $\delta$ is formed initially as laths of varying densities and span depending on strain level, composition, system strain and prior process history. Deformation processing at temperatures below but near the $\delta$ solvus distorts $\delta$. Additional time at temperature, where partial solutioning of $\delta$ occurs, and mechanical work combine to break up the continuity of the lath and chains of tablet and spheroidal shaped $\delta$ begin to appear. When sufficient working and partial solutioning are applied, stable spheroidal $\delta$ particles will result.

\section{Summary}

The objective for this study was to create various $\delta$ morphologies and then observe how further processing evolves the microstructure. The following conclusions can be made from this effort.

Basic origins of complex combinations of $\delta$ phase morphology can be understood through systematic sampling and interpretation of material during the course of its process history.

Residual strain in the system is important to uniform precipitation of $\delta$ phase.

A $\delta$ precipitation heat treatment may be used to understand the existing state of strain in an article of wrought IN 718.

Hot solutioning followed by limited rolling and $\delta$ precipitation heat treatment may reveal segregation patterns if present.

$\mathrm{Nb}$ segregation and near $\delta$ solvus processing may be responsible for the development of duplex grain size distributions in IN 718. Processing to generate more uniform precipitation of $\delta$ phase can be used to develop more uniform grain structures.

A $50 \%$ reduction at $982 \mathrm{C}$ combined with an 8 hour treatment at $899 \mathrm{C}$ is sufficient to convert a partially developed $\delta$ structure into a more complete distribution of short range $\delta$ suitable for further processing.

\section{$\underline{\text { References }}$}

1. E.E. Brown, R.C. Boettner, and D.L. Ruckle, "Minigrain" Processing of Nickel-Base Alloys." Superalloy Processing, Battelle Columbus Laboratories, Columbus, OH MCIC$72-10,1972$.

2. N. A. Wilkinson, "Forging of 718 - The importance of T.M.P.," Superalloy 718 Metallurgy and Applications, ed. E.A. Loria (Warrendale, PA: The Minerals, Metals \& Materials Society, 1989), 119-133. 
3. D.D. Krueger, "The Development of Direct Age 718 for Gas Turbine Engine Disk Applications, "Superalloy 718 - Metallurgy and Applications, ed. E.A. Loria (Warrendale, PA: The Minerals, Metals \& Materials Society, 1989), 279-296.

4. H. L. Eiselstein, "Metallurgy of Columbium-Hardened Nickel-Chromium-Iron Alloy," Advances in the Technology of Stainless Steel and Related Alloys, ASTM STP No. 369 , $62-77,1965$.

5. D. Zhao, P.K. Chaudhury, "Effect of Starting Grain Size on As-Deformed Microstructures in High Temperature Deformation of Alloy 718". Superalloys 718, 625.706 and Various Derivatives, ed. E.A. Loria (Warrendale, PA: The Minerals, Metals \& Materials Society, 1994), 303-317.

6. G. Camus, B. Pieraggi, and F. Chevet, "Hot Deformation and Recrystallization in Inconel 718," Formability and Metallurgical Structure, ed. A. K. Sachdev and J. D. Embury (Warrendale, PA: The Metallurgical Society, 1987), 305-325.

7. R.E. Reed-Hill, Physical Metallurgy Principles $2^{\text {nd }}$ Ed (New York, NY: D. Van Nostrand Company, 1973), p368-375.

8. J. L. Burger, R. R. Biederman, and W. H. Couts, "The Effects of Starting Condition on the Aging Response of As-Forged Alloy 718," Superalloy 718 - Metallurgy and Applications, ed. E.A. Loria (Warrendale, PA: The Minerals, Metals \& Materials Society, 1989), 207217.

9. F.P. Cone, unpublished research, Pratt \& Whitney, United Technologies, West Palm Beach, FL. 